\title{
Inhibition of CXCR4 by CTCE-9908 inhibits breast cancer metastasis to lung and bone
}

\author{
MONICA M. RICHERT ${ }^{1}$, KEDAR S. VAIDYA ${ }^{1}$, CAROLINE N. MILLS $^{1}$, DONALD WONG $^{2}$, \\ WALTER KORZ ${ }^{2}$, DOUGLAS R. HURST ${ }^{1}$ and DANNY R. WELCH ${ }^{1,3}$ \\ ${ }^{1}$ Department of Pathology, University of Alabama at Birmingham, Birmingham, AL, USA; \\ ${ }^{2}$ Chemokine Therapeutics Corp., Vancouver, BC, Canada; ${ }^{3}$ Departments of Cell Biology and \\ Pharmacology/Toxicology and Comprehensive Cancer Center and Center for Metabolic Bone \\ Disease and National Foundation for Cancer Research-Center for Metastasis Research, \\ University of Alabama at Birmingham, Birmingham, AL, USA
}

Received November 6, 2008; Accepted December 2, 2008

DOI: 10.3892/or_00000282

\begin{abstract}
Metastasis occurs, in part, due to tumor cell responses to chemokine secretion by ectopic organs or tissues. SDF-1 is constitutively expressed in tissues where metastases frequently develop while breast carcinoma cells express the receptor for SDF-1, CXCR4, which is correlated with increased bone metastasis and poor overall survival. We hypothesized that treatment with a CXCR4 antagonist, CTCE-9908, would decrease incidence of bone and lung metastasis. Treatment with CTCE-9908 (25 mg/kg) began the day prior to or the day of intravenous or intracardiac tumor cell inoculation of MDA-MB-231 human breast carcinoma cells expressing enhanced green fluorescent protein (GFP) into athymic mice. After 5 or 8 weeks (i.c. and i.v. injections, respectively), the presence of fluorescent foci at metastatic sites was assessed. Somewhat surprisingly, CTCE-9908 treatment did not decrease incidence of metastasis as hypothesized. However, CTCE-9908 did decrease metastatic burden (i.e., size of metastases) in all organs examined (lungs, bone, heart, liver, kidneys, pancreas and spleen). Based upon this and other studies, the use of CTCE-9908 is promising as an adjuvant therapy for metastatic disease.
\end{abstract}

\section{Introduction}

Chemokines are chemoattractant molecules that regulate cellular trafficking (1-4). Secretion of chemokines by tumor cells has been correlated with angiogenesis, tumor growth

Correspondence to: Dr Danny R. Welch, Department of Pathology, 1670 University Blvd, VH-G019, Birmingham, AL 35294-0019, USA

E-mail: danwelch@uab.edu

Key words: CXCR4, CTCE-9908, bone metastasis, breast cancer and metastasis in a variety of experimental and human tumors (reviewed in refs. 1,5). The organotropism of cancer metastasis is believed to occur, at least in part, through secretion of chemokines by distant organs/tissues that direct the migration of tumor cells that come into proximity to the tissue $(1,5)$. SDF-1 (stromal cell derived factor-1) is a chemoattractant for hematopoietic cells to the bone marrow. It is secreted by osteoblasts in marrow stroma $(6,7)$. Secretion of SDF-1 from other organs and at sites of injury facilitates the migration of tissue-committed stem cells that are used for organ regeneration and repair $(7,8)$. Similarly, stem cells are recruited in response to hypoxia-induced HIF1 $\alpha$ promotion of SDF-1 expression (9).

CXCR4 is the major SDF-1/CXCL12 receptor. CXCR4 is highly expressed on hematopoietic cells in peripheral blood as well as early hematopoietic progenitor cells (10). CXCR4 appears to regulate maintenance of hematopoietic progenitor cells in the bone marrow and recruitment to other sites (11). CXCR4 is not expressed to an appreciable level in the normal breast (5). Yet, in atypical ductal hyperplasia, $90 \%$ of samples are positive for CXCR4 expression and it increases as breast cancer progresses to invasive disease $(5,12)$. Increased expression in breast cancer is associated with poor overall survival and more specifically with the development of metastatic disease (reviewed in ref. 13). Correspondingly, SDF-1 is constitutively expressed in tissues where metastases develop, specifically lung, liver and bone $(5,12,14)$. Directed migration of breast cancer cells has been associated with CXCR4 signaling in response to SDF-1 and neutralizing antibodies to CXCR4 can inhibit metastasis of breast cancer to lymph nodes and lung. CXCR4 was identified as one of a small number of genes that were enriched in breast cancer cells selected for increased bone metastasis in an in vivo model (15). Overexpression of CXCR4 alone caused a small, but significant increase in the number of bone metastases, but when combined with expression of IL-11 and osteopontin, CXCR4 expression caused a dramatic increase in incidence and number of bone metastasis. Similarly, expression of CXCR4 in breast cancer patients has been correlated with higher risk of bone 
metastasis (16-18). We note that SDF-1 also binds CXCR7, but the role of CXCR7 in cancer metastasis has not been as well studied; therefore, the studies reported here focus exclusively on CXCR4.

It has been indicated that SDF-1 may affect the tumor microenvironment. It was demonstrated that carcinomaassociated fibroblasts secrete SDF-1 in response to hypoxia which can induce motility and invasiveness in CXCR4 expressing tumor cells $(19,20)$. Also, secretion of SDF-1 by the stroma may promote tumor angiogenesis through the recruitment of hematopoietic endothelial progenitor cells (19). All of these mechanisms may contribute to selective retention of tumor cells at sites of high SDF-1 secretion, such as the bone marrow resulting in the development of metastatic disease.

Collectively, abundant evidence supports multiple roles for CXCR4 and SDF-1 in various steps of cancer metastasis $(2,6)$. The purpose of this study was to test the efficacy of CTCE-9908, a CXCR4 antagonist (21), as an anti-metastatic agent for breast cancer. Previous studies have indicated efficacy of CTCE-9908 as an anti-metastatic to lung (21); however, its efficacy in preventing metastasis to other organs has not yet been evaluated. Since SDF-1 is produced by cells in bone marrow and CXCR4 is aberrantly expressed on metastatic breast cancer cells, we hypothesized that treatment of mice with CTCE-9908 would interfere with 'homing' of breast cancer cells to bone and, therefore, decrease the incidence of bone metastasis. Moreover, since many organs express SDF-1, it was also hypothesized that the incidence of metastasis to other organs would be decreased by treatment with CTCE-9908.

\section{Materials and methods}

Cell lines and culture. Metastatic human breast carcinoma cell line, MDA-MB-231 (MDA-231) was stably transduced with an HIV type 1-based, lentiviral vector system constitutively expressing enhanced GFP (22). For the lentivirus, the GFP coding sequence was inserted into the vector $5^{\prime}$ of the internal ribosome entry site and puromycin sequences, each of which were under control of the early cytomegalovirus promoter. Infectious stocks were prepared by transfection of $293 \mathrm{~T}$ cells and used at a multiplicity of infection of $\sim 10$. Cells were cultured in a mixture $(1: 1$ vol/vol) of DMEM and Ham's F12 media (DMEM/F12; Invitrogen, Carlsbad, CA) supplemented with $2 \mathrm{mmol} / \mathrm{l} \mathrm{L}$ glutamine, $1 \mathrm{mmol} / 1$ sodium pyruvate, $0.02 \mathrm{mmol} / 1$ nonessential amino acids, $5 \%$ fetal bovine serum (Atlanta Biologicals, Norcross, GA), without antibiotics or antimycotics (cDME/F12). All cultures were confirmed to be negative for Mycoplasma spp. infection using a PCR-based test (Takara, Shiga, Japan). The brightest 15\% fluorescing cells were sorted using either Coulter EPICS V cell sorter (Beckman-Coulter, Fullerton, CA) or a BD FACSaria cell sorter (BD Biosciences Immunocytometry Systems, San Jose, CA). The selected cells have remained stable in the absence of selective pressure for more than two years.

Intravenous injections. Cells at $80-90 \%$ confluence were detached using a mixture of $0.5 \mathrm{mmol} / 1$ EDTA and $0.05 \%$

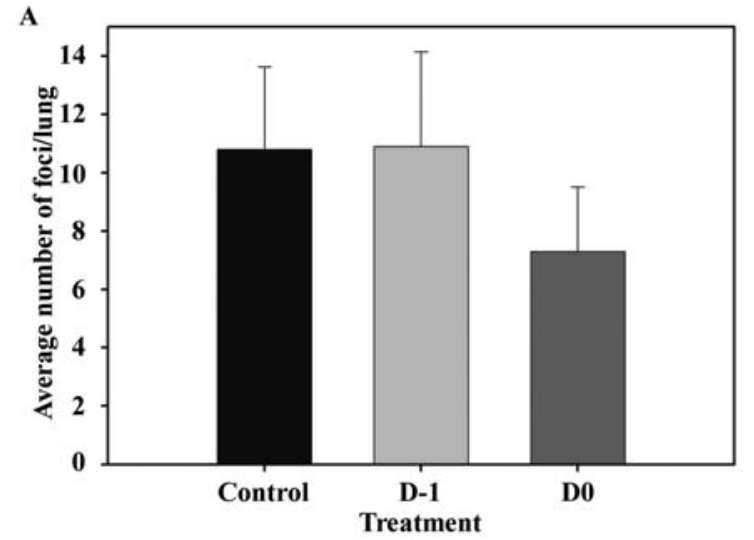

B
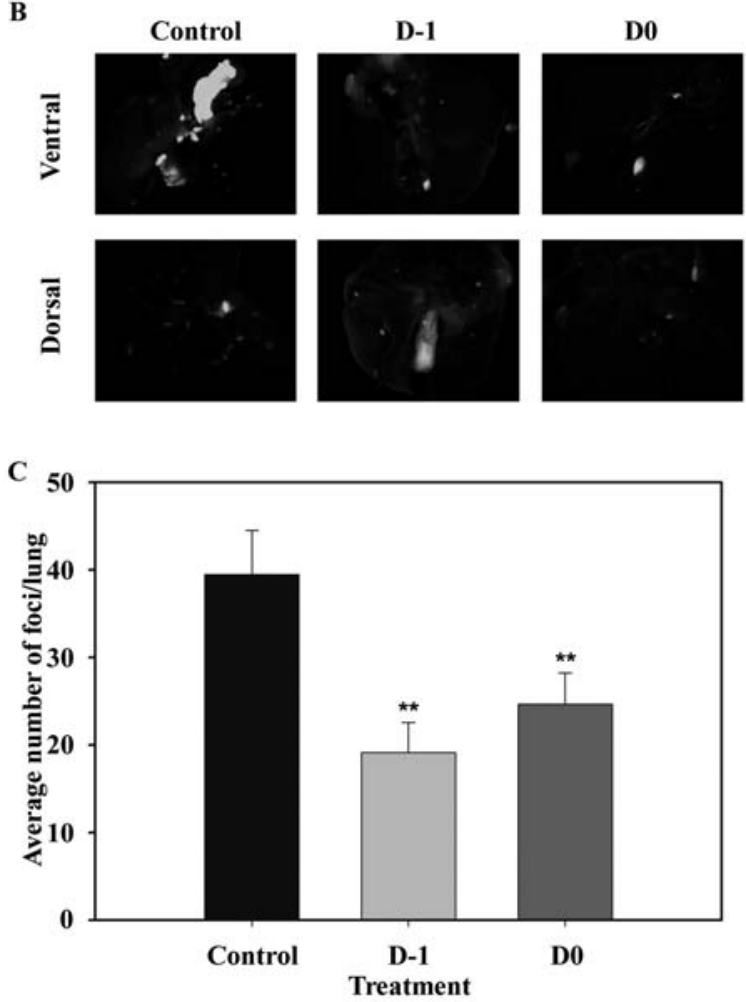

Figure 1. Athymic mice were injected into the tail vein with $2.0 \times 10^{5} \mathrm{GFP}$ expressing MDA-MB-231 cells in $200 \mu 1$ of HBSS. The mice were necropsied 8 weeks later. (A) The number of green fluorescent foci in each lung in each treatment group were counted and the average number of foci per mouse determined. The differences were not statistically significant. (B) Athymic mice were injected into the left cardiac ventricle with $3.0 \times 10^{5}$ GFP-expressing MDA-MB-231 cells in $200 \mu 1$ of HBSS. The mice were necropsied 5 weeks later. Fluorescent photographs were taken of both the dorsal and ventral sides of the lungs from all treatment groups at magnification, $x 1.25$. Representative photos are shown. (C) The green fluorescent foci in each lung from the i.c. injected mice were counted and the average number per mouse for each treatment group was determined. ${ }^{* *} \mathrm{P}<0.05$.

trypsin in $\mathrm{Ca}^{+2}$ - and $\mathrm{Mg}^{+2}$ - and $\mathrm{NaHCO}_{3}$-free $\mathrm{HBSS}$. Cells were not used unless viability was $>95 \%$, but was usually $>98 \%$. Viable cells were counted using a hemacytometer and resuspended at a final concentration of $1.0 \times 10^{6}$ cells $/ \mathrm{ml}$ in ice-cold HBSS. Female athymic mice (3-4 weeks; Harlan Sprague-Dawley, Indianapolis, IN) were briefly restrained while cells $\left(2 \times 10^{5}\right.$ in $\left.0.2 \mathrm{ml}\right)$ were injected into the lateral tail vein. Ten mice were injected per treatment group. 
Table I. Effect of CTCE-9908 on experimental breast cancer lung and bone metastases.

\begin{tabular}{lccc}
\hline & \multicolumn{3}{c}{ Lung foci } \\
Treatment & Route of injection & Incidence & Mean \pm SEM \\
\cline { 2 - 4 } Control & i.v. & $18 / 20$ & $11 \pm 3$ \\
D-1 & i.v. & $20 / 20$ & $11 \pm 3$ \\
D0 & i.v. & $18 / 20$ & $7 \pm 2$ \\
Control & i.c. & $16 / 17$ & $39 \pm 5$ \\
D-1 & i.c. & $16 / 16$ & $19 \pm 3^{\mathrm{a}}$ \\
D0 & i.c. & $12 / 12$ & $25 \pm 4^{\mathrm{a}}$ \\
\cline { 2 - 4 } & & Femur foci & \\
Control & i.c. & $39 / 40$ & $5 \pm 1$ \\
D-1 & i.c. & $37 / 37$ & $7 \pm 1$ \\
D0 & i.c. & $25 / 25$ & $7 \pm 1$ \\
\hline
\end{tabular}

Athymic mice were injected with $2 \times 10^{5}$ cells (i.v.) or $3 \times 10^{5}$ cells (i.c.) and CTCE-9908 (25 mg/kg s.c.) treatment was initiated the same day (D0) or one day preinjection (D-1) and continued until mice were euthanized and necropsied. ${ }^{\mathrm{a}} \mathrm{P}<0.05$.

Intracardiac injections. Viable cells were detached and counted as above using a hemacytometer and resuspended at a final concentration of $1.5 \times 10^{6}$ cells $/ \mathrm{ml}$ in ice-cold HBSS. Female athymic mice (5-6 weeks) were anesthetized by i.m. administration of a mixture of ketamine- $\mathrm{HCl}(129 \mathrm{mg} / \mathrm{kg})$, and xylazine $(4 \mathrm{mg} / \mathrm{kg})$. Cells $\left(3 \times 10^{5}\right.$ in $\left.0.2 \mathrm{ml}\right)$ were injected into the left ventricle of the heart in the third/fourth or fourth/ fifth intracostal space. The presence of bright red- as opposed to burgundy-colored blood prior to and at the end of each inoculation confirmed injection of the entire volume into the arterial system. Twenty mice were injected per treatment group. Intracardiac injections are routinely performed with $>95 \%$ efficiency and $<5 \%$ mortality (23).

Treatments. Mice were injected subcutaneously daily with either $100 \mu \mathrm{l}$ water or $25 \mathrm{mg} / \mathrm{kg}$ CTCE-9908 in $100 \mu \mathrm{l}$ water. Injections were rotated among four to six sites on the dorsolateral flank. This dose was based upon prior in vivo studies and recommended pharmacokinetic studies (21). Treatment was initiated either the day of (D0) or the day prior to tumor cell injection (D-1). These times were chosen because CXCR4 was thought to impact mostly early retention and arrest stages of cancer metastasis.

Mice were weighed weekly to determine the proper amount of CTCE-9908 to administer. Mice were necropsied 5 weeks post-inoculation (for i.c. injected mice) or 8 weeks post-inoculation (for i.v. injected mice) following anesthesia with ketamine/xylazine and euthanasia by cervical dislocation.

Assessment of metastases. For mice injected i.v. with tumor cells, lungs were removed and fixed in Bouin's fixative diluted 1:5 in neutral buffered formalin. Surface metastases were counted by microscopy using a Leica MZFLIII dissecting microscope with $1.0 \mathrm{x}$ objective. The average number of visible metastases per lung was quantified for
A
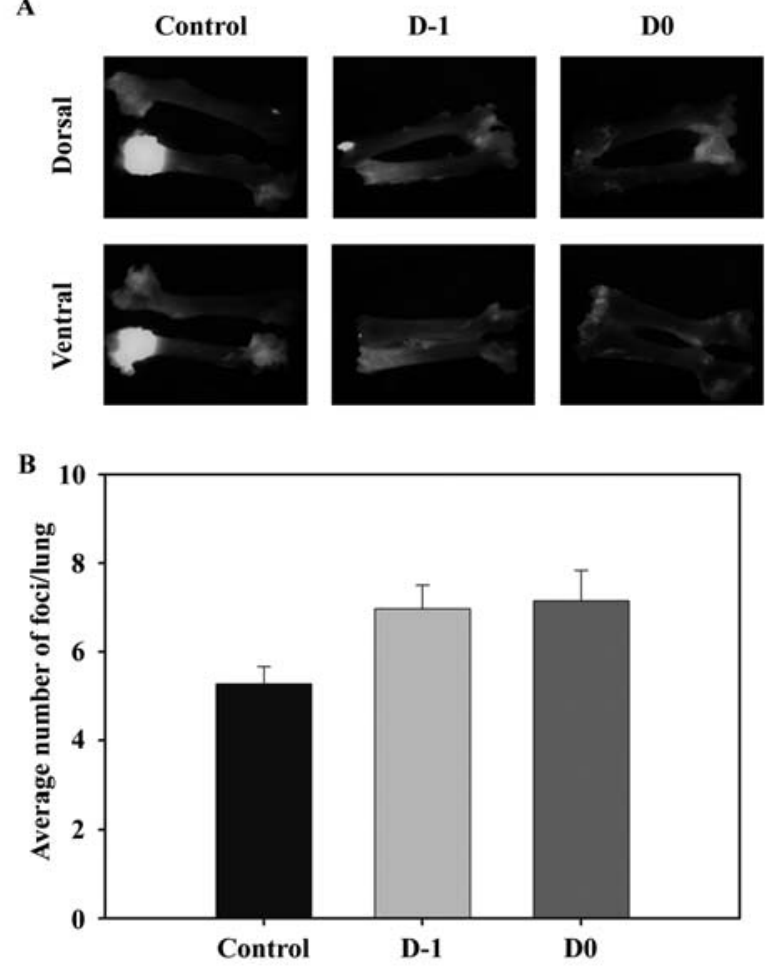

C

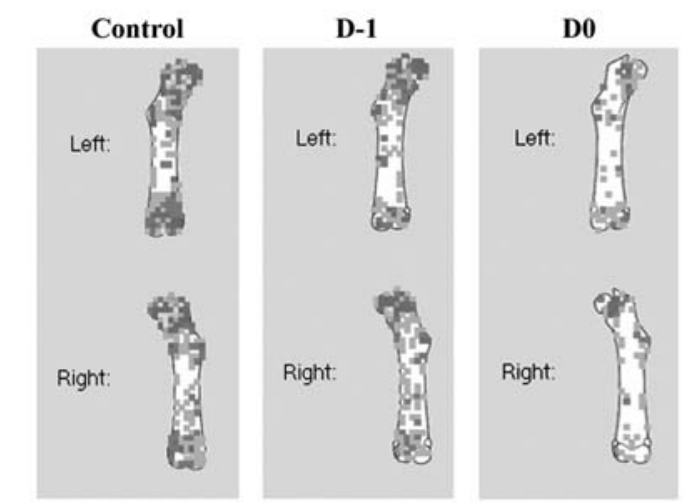

Figure 2. Athymic mice were injected into the left cardiac ventricle with 3.0x $10^{5}$ GFP-expressing MDA-MB-231 cells in $200 \mu 1$ of HBSS. The mice were necropsied 5 weeks later. (A) Fluorescent photographs were taken of both the dorsal and ventral sides of each femur from all treatment groups at magnification, x1.25. Representative photos are shown. (B) The green fluorescent foci in each femur in each treatment group was counted. The average number of foci per femur was determined. (C) The location of each green fluorescent foci was mapped using BoneMetMap (25). (A) The maps for each mouse in each treatment group were merged to show the overall green fluorescence in each treatment group indicating the overall metastatic burden and pattern of metastatic foci for each treatment group.

each treatment group. Incidence of metastasis was reported as the percentage of mice that had $\geq 1$ lung focus. For mice injected i.c. with tumor cells, femurs, ribs, heart, lung, liver, pancreas, spleen, brain, kidneys, uterine horn and ovaries were removed and examined by low magnification fluorescence stereomicroscopy.

Although all tissues were examined, the focus of the i.c. experiments was bone metastasis. Intact, dissected bones and organs from individual mice were placed in $25 \mathrm{ml}$ glass scintillation vials containing freshly prepared, ice-cold $\left(0-4^{\circ} \mathrm{C}\right)$ $4 \%$ paraformaldehyde in $\mathrm{Ca}^{+2}-$ and $\mathrm{Mg}^{+2}$-free Dulbecco's 
Table II. Effect of CTCE-9908 on the incidence and frequency of metastases in multiple organs following injection of MDAMB-231 cells.

Fluorescent foci

\begin{tabular}{lccccccc}
\cline { 2 - 4 } Organ & \multicolumn{3}{c}{ Incidence } & & \multicolumn{3}{c}{ Mean \pm SEM } \\
\cline { 2 - 3 } & Control & D-1 & D0 & & Control & D-1 & D0 \\
\hline Brain & $10 / 17$ & $13 / 15$ & $10 / 12$ & & $4 \pm 1$ & $8 \pm 3$ & $4 \pm 1$ \\
Heart & $16 / 17$ & $14 / 16$ & $11 / 12$ & & $23 \pm 4$ & $14 \pm 4$ & $9 \pm 2$ \\
Liver & $15 / 18$ & $13 / 16$ & $12 / 12$ & $15 \pm 3$ & $7 \pm 2$ & $8 \pm 2$ \\
Spleen & $15 / 17$ & $14 / 16$ & $11 / 11$ & $9 \pm 2$ & $4 \pm 1$ & $4 \pm 2$ \\
Pancreas & $12 / 16$ & $13 / 16$ & $8 / 11$ & $14 \pm 4$ & $9 \pm 2$ & $7 \pm 3$ \\
Uterine horn & $8 / 16$ & $8 / 13$ & $3 / 8$ & & $2 \pm 1$ & $2 \pm 1$ & $1 \pm 1$ \\
Ribs & $16 / 17$ & $16 / 16$ & $12 / 12$ & & $89 \pm 18$ & $48 \pm 10$ & $72 \pm 28$ \\
Kidney & $33 / 36$ & $31 / 32$ & $24 / 24$ & & $14 \pm 2$ & $7 \pm 1$ & $8 \pm 1$ \\
\hline
\end{tabular}

Athymic mice were injected with $3 \times 10^{5}$ cells into the left ventricle of the heart and CTCE-9908 (25 mg/kg s.c.) treatment was initiated the same day (D0) or one day pre-injection (D-1) and continued until mice were euthanized and necropsied. GFP-expressing MDA-MB-231 cells were visualized using a fluorescent stereomicroscope. Fluorescent foci were counted 5 weeks post-injection following organ removal.

PBS. GFP fluorescence was maintained in fixed tissues by maintaining the samples at $4^{\circ} \mathrm{C}(24)$. To visualize metastases derived from the GFP-expressing cell lines, whole femurs (dissected free of soft tissue using a no. 11 scalpel blade with gauze used to grip and remove tissue remnants) were placed into Petri dishes and examined by fluorescence microscopy using a Leica MZFLIII dissecting microscope with 0.7-1.6x objective and GFP fluorescence filters $\left(\lambda_{\text {excitation }}=480 \pm 20 \mathrm{~nm}\right.$; $\lambda_{\text {emission }}=510 \mathrm{~nm}$ barrier; Leica, Deerfield, IL). Photomicrographs were collected using a MagnaFire digital camera (Optronics, Goleta, CA), and ImagePro Plus 5.1 software (Media Cybernetics, Silver Spring, MD). Pictures of the top and bottom of each organ were collected. Incidence of metastasis in each organ was determined by averaging the number of mice with green fluorescent foci in each organ type per treatment group. All green fluorescent foci were counted and averaged across each treatment type to determine the extent of metastasis in each organ as previously described. Finally, the location of green foci in each femur was mapped to determine the patterns of metastasis in the bone, as previously described (25).

Mice were maintained under the guidelines of the NIH and the University of Alabama at Birmingham. All protocols were approved and monitored by the UAB Institutional Animal Care and Use Committee.

\section{Results}

CTCE-9908 is not toxic. Treatment with CTCE-9908 (25 mg/kg) did not cause overt toxicity, except for mild erythema at the site of inoculation, which resolved within a few days. Mice continued to gain weight at rates comparable to vehicle-only treated mice (data not shown). To minimize the impact of the erythema, the location of injection was varied daily among 4-6 sites along the dorsal flank.

CTCE-9908 decreases size, but not incidence, of lung foci. In the mice injected i.v., the incidence of macroscopic lung metastasis was $90 \%$ in control and D0 treated mice and $100 \%$ in the D-1 treated mice (Table I). The number of metastases per lung decreased from 11 in control and D-1 treated mice to 7 in D0 treated mice (Table I; Fig. 1A and B). This change was not statistically significant. In i.c. injected animals, green fluorescent foci [Note: A focus is not necessarily a metastasis. A focus is defined as a green spot greater than or equal to a tumor cell diameter (i.e., $25 \mu \mathrm{m}$ )] were found in all CTCE-9908 treated animals (Table I), while the control group had a $94 \%$ incidence in of foci in the lung. The difference was not statistically significant. However, the number of bona fide metastases per lung significantly decreased from 39 in the untreated, control group to $25(\mathrm{P}=0.022)$ and $19(\mathrm{P}=0.001)$ in the $\mathrm{D} 0$ and $\mathrm{D}-1$ treated groups, respectively (Table I; Fig. 1C). The size of the metastases (>50 cells) also decreased in the CTCE-9908 treated animals (data were not quantified, but representative images illustrate the point).

CTCE-9908 decreases the size of bone and other extrapulmonary foci. The incidence of green fluorescent foci in the femur (98-100\%) did not change significantly when mice were treated with CTCE-9908 (Table I). The number of femur foci increased from 5 in the vehicle-treated mice to 7 $(\mathrm{P}<0.05)$ in both the CTCE-9908 D0 and D-1 treated animals (Table I; Fig. 2A and B). The size of bone metastases was greatly decreased in the CTCE-9908 treated animals (Fig. 2A) compared to vehicle control. Since larger foci obscure the visualization of nearby microscopic foci, the apparent increase in metastasis in the CTCE-9908-treated mice may be artefactual. Overall, metastatic burden was greatest in the control group and lowest in D0 treated animals (Fig. 2C).

The incidence of metastasis decreased in the ovary and uterine horn, but remained the same in all other organs examined (Table II). The number and size of foci in the heart decreased significantly $(\mathrm{P}=0.0061$ for $\mathrm{D} 0$ treatment and $\mathrm{P}=0.0445$ for D-1 treatment; Table II; Fig. 3 ). The number of foci decreased, although not significantly, in the ribs, liver, 


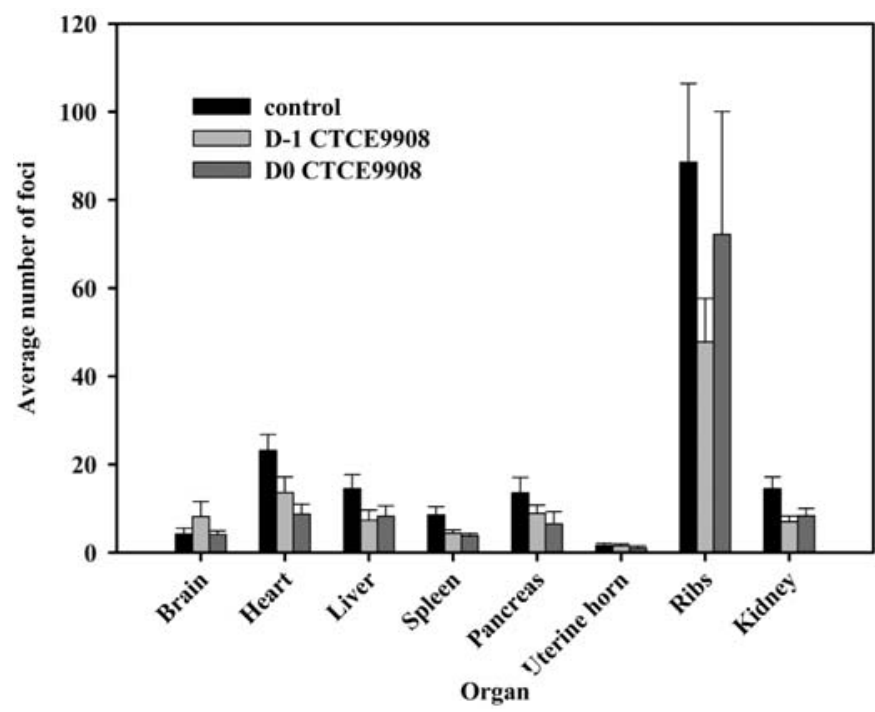

Figure 3. Athymic mice were injected into the left cardiac ventricle with 3.0x $10^{5}$ GFP-expressing MDA-MB-231 cells in $200 \mu 1$ of HBSS. The mice were necropsied 5 weeks later. Fluorescent photographs were taken of the dorsal and ventral aspects of each organ from all treatment groups. For each organ, the green fluorescent foci in each treatment group was counted. The average number of foci per organ was determined.

kidney, pancreas and spleen, while the size was decreased in the liver, but not in other organs (Fig. 3). There was no effect of CTCE-9908 on brain metastasis (Table II; Fig. 3).

\section{Discussion}

Based upon differential tissue expression and high expression in bone, we hypothesized that the incidence of metastasis to bone, and perhaps other organs, would decrease upon treatment with the CXCR4 antagonist, CTCE-9908. Unexpectedly, with the exception of the uterine horn and the ovary (Fig. 3), treatment did not affect the incidence of metastasis. Instead, in most cases, the number of foci per organ decreased and there was a dramatic decrease in the size of the foci in mice treated with CTCE-9908.

While the number of lung metastases after i.v. injection did not change significantly, occasional lung metastases following i.c. injection were significantly lower. The frequency of lung metastases is generally low following i.c. injection; so, the higher-than-expected frequency of foci observed in this study were likely due, in part, to leakage into the pleural cavity during the injection process (25). Regardless of the mechanism of seeding, it appears that CTCE-9908 was able to decrease the tumor burden in the lungs.

Bone metastases are reported for the femur because, in previous studies, the development of bone metastases elsewhere in the body was parallel to the size and incidence of osteolytic lesions in femurs $(22,23)$. Although the number of fluorescent foci was slightly higher in the CTCE-9908 treated mice (Table I; Fig. 2A), visualization of individual cells was likely due to the decreased macroscopic lesions, thereby allowing easier visualization of single cells. Combinatorial analyses of the bone lesions (25) revealed that occupancy by tumor cells was significantly lower in CTCE-9908 treated mice (Fig. 2C), especially when treatment began contemporaneously with tumor cell inoculation (i.e., D0).

The distinction between fluorescent foci, which can represent single cells to macroscopic metastatic foci, is critical. It is well known that solid tumors can release millions of tumor cells daily, even from small masses. However, the formation of clinically relevant metastasis is infrequent. The initial seeding of various organs is much less relevant from a clinical perspective than the formation of macroscopic lesions $(13,26)$. Interpretation of the data presented in this study is impacted greatly by these considerations. We have advocated previously that a metastasis be defined as a mass of $\geq 50$ cells (26), which is used consistently in this study. While that definition may be open for discussion, the principles guide our presentation and interpretation of data presented herein.

Previous studies show efficacy of CTCE-9908 in decreasing formation of lung metastases from osteosarcoma and melanoma (21). However, in contrast to the previous study, pretreatment of breast cancer cells or mice with CTCE9908 was not required. Importantly, data with MDA-MB-231 cells demonstrate that inhibition of CXCR4 substantially decreased metastatic burden in multiple organs, but most significantly in the bone.

Based upon the known roles of CXCR4 in hematopoiesis, inhibition of CXCR4 signaling would be predicted to alter adhesion, invasion, migration, 'homing' and/or growth rate of neoplastic cells. Impairment of tumor cells to adhere, invade and grow was observed previously (21). However, the data using the MDA-MB-231 cells suggest that the role(s) of CXCR4 in breast cancer metastasis may be more complex. Based upon the modest changes in the incidence of metastases (and individual tumor cell foci), antagonism of CXCR4 does not appear to abolish mechanical arrest of cancer cells. The decrease in focus number and numbers of metastases may be explained, in part, by CTCE-9908 induction of anoikis in the circulation or apoptosis subsequent to arrival at some secondary sites $(21,27,28)$. The hypothesis that SDF-1 and CXCR4 are involved in tumor cell 'homing' is not borne out by the data obtained in this study. This conclusion is based upon known differences in SDF-1 expression in various tissues (5), but a relatively uniform retention of fluorescent foci in virtually every site.

CXCR4 may affect survival and/or proliferation of tumor cells once they arrive at the secondary site(s) (27-33). This possibility is supported by a consistent decrease in the size of fluorescent foci in every tissue when mice were treated with CTCE-9908. This interpretation is consistent with prior studies showing that the proliferation of tumor cells in vivo was affected by CXCR4 expression $(27,34,35)$. Also, CTCE9908 has been shown to decrease the growth of osteosarcoma and melanoma cells both in vitro and in vivo (21). The design of the studies reported here preclude assessment of whether individual seeded cells grew to form macroscopic colonies vs. whether individual cells coalesced for form larger foci. Another intriguing explanation for diminished growth of disseminated cells is based upon recent findings that CXCR4 is involved in the recruitment of hematopoietic endothelial progenitor cells to tumor microenvironments (19). Since tumors cannot grow beyond a few hundred micrometers 
without establishment of a robust blood supply (36-38), treatment with CTCE-9908 may prevent angiogenesis of micrometastases, preventing conversion to overt metastases (i.e., colonization).

The data presented herein support important roles for CXCR4 in cancer metastasis. Moreover, the data strongly support further development of CTCE-9908 as an antimetastatic agent. Since metastasis is the most lethal and most morbidity-inducing attribute of cancer cells, control of metastasis offers great potential for improving survival and patient quality of life (13).

Arguments against metastasis as a rational therapeutic target have centered upon the probability that most antecedent steps of the metastatic cascade have occurred by the time of primary tumor discovery (13). The data presented herein implicate CXCR4 in the last step of metastasis, colonization. In support of this notion is accumulating data related to several metastasis suppressors, including BRMS1 and KISS1. Both metastasis suppressors significantly reduce (or prohibit) tumor cell proliferation in ectopic sites $(22,39)$. Intriguingly, BRMS 1 and KISS 1 both regulate CXCR4 signaling $(40,41)$. In non-small cell lung cancer, BRMS1 reduces CXCR4 expression through inhibition of $\mathrm{NFKB}$ resulting in an inhibition of SDF-1 induced migration (40). BRMS1 and CXCR4 are also inversely correlated in non-small cell lung cancer cases indicating that one mechanisms of BRMS1 suppression of metastasis is downregulation of CXCR4. KISS1, and protease cleavage-derived kisspeptins, prevent SDF-1 induced CXCR4 chemotaxis (41). While further studies will be required to establish definitive connections between CXCR4, KISS1/BRMS1 and metastasis suppression, the implications provide testable hypotheses regarding mechanisms of metastasis suppression.

\section{Acknowledgements}

This work was performed primarily by a grant to D.R.W. from Chemokine Therapeutics, Corp. However, partial support from the National Cancer Institute (CA87728 to D.R.W. and CA113037 to D.R.H.) and Susan G. Komen for the Cure (PDF1122006 to K.S.V.) supported salaries. We are grateful to members of the Welch laboratory for assistance with various aspects of this project and for helpful discussions.

\section{References}

1. Dittmar T, Heyder C, Gloria-Maercker E, Hatzmann W and Zanker KS: Adhesion molecules and chemokines: the navigation system for circulating tumor (stem) cells to metastasize in an organ-specific manner. Clin Exp Metastasis 25: 11-32, 2008.

2. Busillo JM and Benovic JL: Regulation of CXCR4 signaling. Biochim Biophys Acta Biomemb 1768: 952-963, 2007.

3. Faber A, Roderburg C, Wein F, Saffrich R, Seckinger A, Horsch K, Diehlmann A, Wong D, Bridger G, Eckstein V, Ho AD and Wagner W: The many facets of SDF-1alpha, CXCR4 agonists and antagonists on hematopoietic progenitor cells. J Biomed Biotechnol 2007: 260-265, 2007.

4. Murdoch C: CXCR4: chemokine receptor extraordinaire. Immunol Rev 177: 175-184, 2000.

5. Muller A, Homey B, Soto H, Ge NF, Catron D, Buchanan ME, McClanahan T, Murphy E, Yuan W, Wagner SN, Barrera JL, Mohar A, Verastegui E and Zlotnik A: Involvement of chemokine receptors in breast cancer metastasis. Nature 410: 50-56, 2001 .
6. Wang J, Loberg R and Taichman RS: The pivotal role of CXCL12 (SDF-1)/CXCR4 axis in bone metastasis. Cancer Metastasis Rev 25: 573-587, 2006.

7. Kucia M, Reca R, Miekus K, Wanzeck J, Wojakowski W, Janowska-Wieczorek A, Ratajczak J and Ratajczak MZ: Trafficking of normal stem cells and metastasis of cancer stem cells involve similar mechanisms: Pivotal role of the SDF-1CXCR4 axis. Stem Cells 23: 879-894, 2005.

8. Kucia M, Ratajczak J, Reca R, Janowska-Wieczorek A and Ratajczak MZ: Tissue-specific muscle, neural and liver stem/ progenitor cells reside in the bone marrow, respond to an SDF-1 gradient and are mobilized into peripheral blood during stress and tissue injury. Blood Cells Mol Dis 32: 52-57, 2004.

9. Ceradini DJ, Kulkarni AR, Callaghan MJ, Tepper OM, Bastidas N, Kleinman ME, Capla JM, Galiano RD, Levine JP and Gurtner GC: Progenitor cell trafficking is regulated by hypoxic gradients through HIF-1 induction of SDF-1. Nature Med 10: 858-864, 2004.

10. Aiuti A, Tavian M, Cipponi A, Ficara F, Zappone E, Hoxie J, Peault B and Bordignon C: Expression of CXCR4, the receptor for stromal cell-derived factor-1 on fetal and adult human lymphohematopoietic progenitors. Eur J Immunol 29: 1823-1831, 1999.

11. Aiuti A, Webb IJ, Bleul C, Springer T and Gutierrez-Ramos JC: The chemokine SDF-1 is a chemoattractant for human CD34 ${ }^{+}$ hematopoietic progenitor cells and provides a new mechanism to explain the mobilization of $\mathrm{CD} 34^{+}$progenitors to peripheral blood. J Exp Med 185: 111-120, 1997.

12. Cabioglu N, Sahin A, Doucet M, Yavuz E, Igci A, Yildirim EO, Aktas E, Bilgic S, Kiran B, Deniz G and Price JE: Chemokine receptor CXCR4 expression in breast cancer as a potential predictive marker of isolated tumor cells in bone marrow. Clin Exp Metastasis 22: 39-46, 2005.

13. Eccles SA and Welch DR: Metastasis: recent discoveries and novel treatment strategies. Lancet 369: 1742-1757, 2007.

14. Taichman RS, Cooper C, Keller ET, Pienta KJ, Taichman NS and McCauley LK: Use of the stromal cell-derived factor-1/ CXCR4 pathway in prostate cancer metastasis to bone. Cancer Res 62: 1832-1837, 2002.

15. Kang YB, Siegel PM, Shu WP, Drobnjak M, Kakonen SM, Cordón-Cardo C, Guise TA and Massagué J: A multigenic program mediating breast cancer metastasis to bone. Cancer Cell 3: 537-549, 2003.

16. Cheng $X$ and Hung MC: Breast cancer brain metastases. Cancer Metastasis Rev 26: 635-643, 2007

17. Koizumi K, Hojo S, Akashi T, Yasumoto K and Saiki I: Chemokine receptors in cancer metastasis and cancer cellderived chemokines in host immune response. Cancer Sci 98: 1652-1658, 2007

18. Luker KE and Luker GD: Functions of CXCL12 and CXCR4 in breast cancer. Cancer Lett 238: 30-41, 2006.

19. Kaplan RN, Riba RD, Zacharoulis S, Bramley AH, Vincent L, Costa C, MacDonald DD, Jin DK, Shido K, Kerns SA, Zhu Z, Hicklin D, Wu Y, Port JL, Altorki N, Port ER, Ruggero D, Shmelkov SV, Jensen KK, Rafii S and Lyden D: VEGFR1positive haematopoietic bone marrow progenitors initiate the pre-metastatic niche. Nature 438: 820-827, 2005.

20. Begley L, Monteleon C, Shah RB, MacDonald JW and Macoska JA: CXCL12 overexpression and secretion by aging fibroblasts enhance human prostate epithelial proliferation in vitro. Aging Cell 4: 291-298, 2005.

21. Kim SY, Lee CH, Midura BV, Yeung C, Mendoza A, Hong SH, Ren L, Wong D, Korz W, Merzouk A, Salari H, Zhang H, Hwang ST, Khanna C and Helman LJ: Inhibition of the CXCR4/CXCL12 chemokine pathway reduces the development of murine pulmonary metastases. Clin Exp Metastasis 25: 201-211, 2008.

22. Phadke PA, Vaidya KS, Nash KT, Hurst DR and Welch DR: BRMS1 suppresses breast cancer experimental metastasis to multiple organs by inhibiting several steps of the metastatic process. Am J Pathol 172: 809-817, 2008

23. Phadke PA, Mercer RR, Harms JF, Jia Y, Frost AR, Jewell J, Bussard KM, Nelson S, Moore C, Kappes JC, Gay CV, Mastro AM and Welch DR: Kinetics of metastatic breast cancer cell trafficking in bone. Clin Cancer Res 12: 1431-1440, 2006.

24. Harms JF, Budgeon LR, Christensen ND and Welch DR: Maintaining green fluorescent protein tissue fluorescence through bone decalcification and long-term storage. Biotechniques 33: 1197-1200, 2002

25. Harms JF and Welch DR: MDA-MB-435 human breast carcinoma metastasis to bone. Clin Exp Metastasis 20: 327-334, 2003. 
26. Welch DR: Do we need to redefine a cancer metastasis and staging definitions? Breast Disease 26: 3-12, 2007.

27. Smith MCP, Luker KE, Garbow JR, Prior JL, Jackson E, Piwnica-Worms D and Luker GD: CXCR4 regulates growth of both primary and metastatic breast cancer. Cancer Res 64: 8604-8612, 2004

28. Nishio M, Endo T, Tsukada N, Ohata J, Kitada S, Reed JC, Zvaifler NJ and Kipps TJ: Nurselike cells express BAFF and APRIL, which can promote survival of chronic lymphocytic leukemia cells via a paracrine pathway distinct from that of SDF-1alpha. Blood 106: 1012-1020, 2005.

29. Burger M, Hartmann T, Krome M, Rawluk J, Tamamura H, Fujii N, Kipps TJ and Burger JA: Small peptide inhibitors of the CXCR4 chemokine receptor (CD184) antagonize the activation, migration, and antiapoptotic responses of CXCL12 in chronic lymphocytic leukemia B cells. Blood 106: 1824-1830, 2005.

30. Marchesi F, Monti P, Leone BE, Zerbi A, Vecchi A, Piemonti L, Mantovani A and Allavena P: Increased survival, proliferation, and migration in metastatic human pancreatic tumor cells expressing functional CXCR4. Cancer Res 64: 8420-8427, 2004.

31. Zhou Y, Larsen PH, Hao C and Yong VW: CXCR4 is a major chemokine receptor on glioma cells and mediates their survival J Biol Chem 277: 49481-49487, 2002.

32. Ma Q, Jones D, Borghesani PR, Segal RA, Nagasawa T, Kishimoto T, Bronson RT and Springer TA: Impaired Blymphopoiesis, myelopoiesis, and derailed cerebellar neuron migration in CXCR4- and SDF1-deficient mice. Proc Natl Acad Sci 95: 9448-9453, 1998.

33. Nagasawa T, Hirota S, Tachibana K, Takakura N, Nishikawa S, Kitamura Y, Yoshida N, Kikutani H and Kishimoto T: Defects of B-cell lymphopoiesis and bone-marrow myelopoiesis in mice lacking the CXC chemokine PBSF/SDF-1. Nature 382: 635-638, 1996.
34. Ben-Baruch A: Host microenvironment in breast cancer development: inflammatory cells, cytokines and chemokines in breast cancer progression: reciprocal tumor-microenvironment interactions. Breast Cancer Res 5: 31-36, 2003.

35. Kulbe H, Levinson NR, Balkwill F and Wilson JL: The chemokine network in cancer - much more than directing cell movement. Int J Dev Biol 48: 489-496, 2004.

36. Folkman J: Angiogenesis. Annu Rev Med 57: 1-18, 2006

37. Naumov GN, Bender E, Zurakowski D, Kang SY, Sampson D Flynn E, Watnick RS, Straume O, Akslen LA, Folkman J and Almog N: A model of human tumor dormancy: an angiogenic switch from the nonangiogenic phenotype. J Natl Cancer Inst 98: 316-325, 2006.

38. Naumov GN, Akslen LA and Folkman J: Role of angiogenesis in human tumor dormancy - animal models of the angiogenic switch. Cell Cycle 5: 1779-1787, 2006.

39. Nash KT, Phadke PA, Navenot J-M, Hurst DR, Accavitti-Loper MA Sztul E, Vaidya KS, Frost AR, Kappes JC, Peiper SC and Welch DR: KISS1 metastasis suppressor secretion, multiple organ metastasis suppression, and maintenance of tumor dormancy. J Natl Cancer Inst 99: 309-321, 2007.

40. Yang J, Zhang B, Lin Y, Yang Y, Liu X and Lu F: Breast cancer metastasis suppressor 1 inhibits SDF-1alpha-induced migration of non-small cell lung cancer by decreasing CXCR4 expression. Cancer Lett 269: 46-56, 2008.

41. Navenot JM, Wang Z, Chopin M, Fujii N and Peiper SC: Kisspeptin-10-induced signaling of GPR54 negatively regulates chemotactic responses mediated by CXCR4: a potential mechanism for the metastasis suppressor activity of kisspeptins. Cancer Res 65: 10450-10456, 2005. 